\title{
Genetic parameters for claw and leg health, foot and leg conformation, and locomotion in Danish Holsteins
}

\author{
M. V. Laursen, ${ }^{*}$ D. Boelling, $\dagger$ and T. Mark ${ }^{* 1}$ \\ *Department of Basic Animal and Veterinary Sciences, Faculty of Life Sciences, University of Copenhagen, Grønnegårdsvej 3 , \\ 1870 Frederiksberg C, Denmark \\ †National Centre, the Danish Cattle Federation, Department of Breeding Systems, Udkærsvej 15, 8200 Aarhus N, Denmark
}

\begin{abstract}
The purpose of this study was to estimate the genetic correlations among claw and leg health and potential indicator traits. Claw health was defined as absence of heel horn erosion, interdigital dermatitis, interdigital phlegmon, interdigital hyperplasia, laminitis, and sole ulcer. Leg health was defined as absence of hock infection, swollen hock, and bruising. The potential indicators were locomotion and foot and leg conformation, represented by rear leg side view, rear leg rear view, foot angle, and apparent hock quality and bone structure. The study was conducted using records from 429,877 Danish Holstein cows in first lactation. Binary health traits were divided into 3 subcategories: claw health, leg health, and absence of all claw and leg disorders. Genetic $\left(\mathrm{r}_{\mathrm{g}}\right)$ and phenotypic correlations were estimated using a bivariate linear sire model and REML. Estimated heritabilities were 0.01 for all 3 combined claw and leg health traits (on the observed binary scale), 0.09 for locomotion, 0.14 for rear leg rear view, 0.19 for rear leg side view, 0.13 for foot angle, 0.22 for apparent hock quality, and 0.27 for apparent bone structure. Heritabilities were 0.06 and 0.01 for claw health and leg health, respectively, when transformed to the underlying continuous scale. Claw and leg disorders are an increasing problem for Danish Holsteins, but genetic improvement of claw and leg health is challenging because the traits have low heritabilities. Claw and leg health were separate but correlated traits $\left(r_{g}=0.35\right)$. Locomotion and rear leg rear view were useful indicator traits for claw health $\left(r_{g}=0.46\right.$ and $r_{g}$ $=0.21$, respectively), whereas hock quality and bone structure were useful indicators for leg health $\left(\mathrm{r}_{\mathrm{g}}=0.42\right.$ and 0.26 , respectively). Claw and leg health should be considered as separate traits in genetic evaluations that also include the useful indicator traits to compensate for low heritability of the health traits.
\end{abstract}

Received May 23, 2008.

Accepted November 25, 2008.

${ }^{1}$ Corresponding author: thm@life.ku.dk
Key words: claw health, leg health, locomotion, genetic correlation

\section{INTRODUCTION}

Claw and leg disorders are an increasing problem in Danish Holstein herds. Impaired mobility from a claw disorder or, more rarely, a leg disorder is associated, both directly and indirectly, with considerable costs. The direct costs are related to treatment of the disorder. Indirect costs include loss of milk production, impaired fertility, and premature involuntary culling (Green et al., 2002; Booth et al., 2004; Garbarino et al., 2004). Furthermore, claw and leg disorders reduce the welfare of an animal (e.g., Alban, 1994). Consequently, claw and leg disorders are the third most expensive disorder or dysfunction, exceeded only by mastitis and infertility (Enting et al., 1997). Ettema and Østergaard (2006) estimated that clinical lameness, on average, entailed a loss of €192 per first case incident, under Danish conditions.

Claw and leg health is affected by both environmental and genetic factors. Environmental factors such as housing and management routines have the greatest effect because the heritability of claw and leg health is low ( $\leq 0.1$; van der Waaij et al., 2005; Strudsholm et al., $2007)$. However, long-term improvement of claw and leg health can be accomplished by genetic selection. In the Nordic countries, breeding for claw and leg health is carried out by using the Nordic total-merit index. That index makes use of a sub-index for all health traits that considers claw and leg disorders as a combined trait. A sub-index for foot and leg conformation traits is also included in the Nordic total merit index, but the genetic correlations with claw and leg health are unknown and not accounted for. However, it might be desirable to use correlated information from locomotion or conformation traits, because more animals have conformation records than health records and because conformation data are available earlier. Therefore, the objective of this study was to estimate the genetic correlations among claw and leg health, locomotion, and foot and leg conformation traits. 
Table 1. A list of disorders divided into 3 subcategories

\begin{tabular}{ll}
\hline Trait & Disorders \\
\hline Claw disorders & $\begin{array}{c}\text { Heel horn erosion, interdigital dermatitis, interdigital phlegmon, } \\
\text { interdigital hyperplasia, laminitis, sole ulcer } \\
\text { Leg disorders }\end{array}$ \\
$\begin{array}{l}\text { Hock infection, swollen hocks, bruising } \\
\text { All claw and leg disorders }\end{array}$ & All disorders including undefined leg disorders \\
\hline
\end{tabular}

\section{MATERIALS AND METHODS}

\section{Data}

The study was performed using data from Danish Holstein cows in first lactation, calving from January 2004 to April 2007. The records of conformation, locomotion, and claw and leg disorders were extracted from the Danish Cattle Database (Danish Cattle, Skejby, Denmark).

\section{Claw and Leg Health Data}

The recordings for claw and leg health, defined as absence of disorder (yes $=1$, no $=0$ ), were performed by veterinarians. Nine different claw and leg disorders were registered. In this study, the disorders were divided in 3 separate subcategories: absence of claw disorders (claw health), absence of leg disorders (leg health), and absence of all claw and leg disorders. The subcategories are described further in Table 1. The latter subcategory included disorders from the 2 former subcategories and recordings for undefined claw and leg disorders.

Herds had to have at least 0.3 registered treatments (any disease) per calving on average to ensure a reliable recording scheme; otherwise, the recordings were excluded from the data set. This generated a data set consisting of records from 589,474 cows. Recordings from cows with calving age $<21$ mo and $>35$ mo were deleted, retaining 566,383 recordings. Second and later health recordings were omitted, leaving 426,169 records. Finally, 4,074 records from herds with $<5$ recordings for a claw and leg disorder per year were excluded.

The data editing reduced the data set to 422,095 recordings for cows with or without claw and leg disorders (1 record per cow). Six percent of the cows had at least one of the claw and leg disorders (Table 2). The combined subcategory with the highest disease incidence was claw health. The frequency of leg disorders accounted for only one-fourth of all claw and leg disorders. The individual disorder with the highest incidence was interdigital phlegmon.

\section{Locomotion and Conformation Data}

Locomotion data considered in this study were recorded on a trial basis from August 2004 to April
2007 by 6 trained classifiers. About $40 \%$ of all herds were suitable for locomotion scoring. For the remaining herds, insufficient space or tie stalls prevented locomotion scoring. Although locomotion was of primary interest in this study, estimation of genetic parameters for foot and leg conformation were also included for the same cows that had locomotion recorded. The conformation traits considered here were rear leg side view (RLSV), rear leg rear view (RLRV), foot angle, and apparent hock quality and bone structure. These were scored by the same trained classifiers that scored locomotion. Locomotion and the conformation traits were recorded using a 9-point scale (Table 3 and Table 4) during first lactation and not later than 14 mo after first calving. To ensure consistency in the scoring of the conformation data, the classifiers trained together once a year to be able to score the cows uniformly. The data set containing records for locomotion and conformation traits had 56,438 records for Holstein cows.

\section{Final Data}

The data set containing claw and leg health records and the data set containing records for conformation traits and locomotion were merged, creating a final data set comprising 429,877 cows in 4,212 herds. Thus, some animals had missing records for one or more of the recorded traits. All animals were purebred Holsteins with known sires.

Table 2. Percentage of $\operatorname{cows}^{1}$ with certain disorders

\begin{tabular}{lc}
\hline Disorder & Cows, $\%$ \\
\hline Specific disorders & \\
Interdigital dermatitis & 0.27 \\
Heel horn erosion & 0.10 \\
Interdigital phlegmon & 2.91 \\
Interdigital hyperplasia & 0.01 \\
Laminitis & 0.09 \\
Hook infection & 0.22 \\
Sole ulcer & 0.18 \\
Bruising & 0.10 \\
Swollen hook & 1.06 \\
Undefined leg disorder & 2.02 \\
Group of disorders & \\
Claw disorders & 3.52 \\
Leg disorders & 1.37 \\
All claw and leg disorders & 6.30 \\
\hline
\end{tabular}

${ }^{1}$ Percentage of all first-parity cows included in the analyses. 
Table 3. Description of the Danish locomotion scoring system

\begin{tabular}{llll}
\hline Score $^{1}$ & Movement of legs & Step length & Gait \\
\hline 1 & Lame & Lame & Lame \\
2 & Very severe abduction/adduction & Short & Very uneven \\
3 & Severe abduction/adduction & Short & Uneven \\
4 & Severe abduction/adduction & Medium & Uneven \\
5 & No abduction/adduction & Short & Even \\
6 & Slight abduction/adduction & Medium & Even \\
7 & Slight abduction/adduction & Long & Even \\
8 & No abduction/adduction & Medium & Even \\
9 & No abduction/adduction & Long & Even \\
\hline
\end{tabular}

${ }^{1}$ The optimum score for locomotion is 9 .

\section{Statistical Analysis}

Genetic parameters for claw health, leg health, individual disorders, foot and leg conformation traits and locomotion were estimated using the average information (AI) REML procedure (Jensen et al., 1997) as implemented in the DMU package (Madsen and Jensen, 1993). The bivariate sire model, used for the estimation of genetic correlations, was as follows:

$$
\left[\begin{array}{l}
\mathrm{y}_{1} \\
\mathrm{y}_{2}
\end{array}\right]=\left[\begin{array}{ll}
\mathrm{x}_{1} & 0 \\
0 & \mathrm{X}_{2}
\end{array}\right]\left[\begin{array}{l}
\mathrm{b}_{1} \\
\mathrm{~b}_{2}
\end{array}\right]+\left[\begin{array}{ll}
\mathrm{z}_{1} & 0 \\
0 & \mathrm{z}_{2}
\end{array}\right]\left[\begin{array}{l}
\mathrm{s}_{1} \\
\mathrm{~s}_{2}
\end{array}\right]+\left[\begin{array}{l}
\mathrm{e}_{1} \\
\mathrm{e}_{2}
\end{array}\right]
$$

where $\mathbf{y}_{1}$ was observations for the health trait of interest and $\mathbf{y}_{2}$ was observations for the indicator trait; $\mathbf{s}=\left[\begin{array}{l}\mathbf{s}_{1} \\ \mathbf{s}_{2}\end{array}\right] \sim \mathrm{N}\left(\mathbf{0}, \mathbf{G}_{0} \otimes \mathbf{A}\right)$, where $\mathbf{G}_{0}=\left[\begin{array}{cc}\sigma_{\mathrm{s} 1}^{2} & \sigma_{\mathrm{s} 12} \\ \sigma_{\mathrm{s} 21} & \sigma_{\mathrm{s} 2}^{2}\end{array}\right], \otimes$ denotes the Kronecker product, and $\mathbf{A}$ is the additive genetic relationship matrix among sires; $\mathbf{e}=\left[\begin{array}{l}\mathbf{e}_{1} \\ \mathbf{e}_{2}\end{array}\right]$ $\sim \mathrm{N}\left(\mathbf{0}, \mathbf{R}_{0} \otimes \mathbf{I}\right)$, where $\mathbf{R}_{0}=\left[\begin{array}{cc}\sigma_{\mathrm{e} 1}^{2} & \sigma_{\mathrm{e} 12} \\ \sigma_{\mathrm{e} 21} & \sigma_{\mathrm{e} 2}^{2}\end{array}\right]$, and $\mathbf{I}$ is the identity matrix of appropriate size. Relationships were traced back 5 generations. Further, $\mathbf{X}_{1}$ and $\mathbf{X}_{2}$ are design matrices associating the fixed effects $\mathbf{b}_{1}$ and $\mathbf{b}_{2}$ to $\mathbf{y}_{1}$ and $\mathbf{y}_{2}$, respectively. The design matrices $\mathbf{Z}_{1}$ and $\mathbf{Z}_{2}$ associate sires to observations, and $\mathbf{e}_{1}$ and $\mathbf{e}_{2}$ are the random residuals.

The fixed effects were all defined as class variables. The fixed effects $\left(\mathbf{b}_{1}\right)$ for the health trait of interest were herd-year (13,690 classes; 5 to 302 observations/ class), season (4 classes; 85,013 to 124,949 observations/class), calving age in months (16 classes; 1,216 to 68,562 observations/class), and calving-year-period (8 classes; 4,859 to 65,704 observations/class).

Different fixed effects were modeled for the indicator trait $\left(\mathbf{b}_{2}\right)$. These were herd-year $(2,405$ classes; 5 to 178 observations/class), calving month (12 classes; 3,815 to 6,032 observations/class), calving age in months (16 classes; 44 to 10,952 observations/class), stage of lactation in months (14 classes; 41 to 12,240 observations/class), classifier-year-month (147 classes; 62 to 797 observations/class), and year-region (37 classes; 26 to 5,309 observations/class). The term region was created by dividing Denmark into 10 regions. In total, 28 bivariate analyses were performed. Heritabilities and variance components were also estimated with similar univariate models.

Selection index calculations using the estimated genetic parameters for 2 example bulls with 10 and 100 daughter-records per trait (only 5 and 50 for locomotion), respectively, were performed to illustrate the approximate gain in accuracy of selection for claw health by considering locomotion and RLRV as indicators.

To compare the estimated heritabilities on the observed binary scale with certain results from the litera-

Table 4. Description of the Danish scoring scale for conformation traits

\begin{tabular}{llc}
\hline Trait $^{1}$ & Description & Optimum \\
\hline RLSV & $1=$ straight $, \ldots, 9=$ sickled & 5 \\
RLRV & $1=$ toes out $, \ldots, 9=$ bow legged & 8 \\
HQ & $1=$ with cartilage $, \ldots, 9=$ dry & 9 \\
BS & $1=$ very coarse bones $, \ldots, 9=$ very fine & 8 \\
FA & $1=$ very low angle $, \ldots, 9=$ very steep angle & 6.5 \\
\hline
\end{tabular}

${ }^{1}$ RLSV = rear leg side view; RLRV = rear leg rear view; HQ = apparent hock quality; BS = apparent bone structure; $\mathrm{FA}=$ foot angle. 
Table 5. Mean, standard deviation (SD), skewness, and kurtosis for conformation traits and locomotion

\begin{tabular}{lcccc}
\hline Trait $^{1}$ & Mean & SD & Skewness & Kurtosis \\
\hline Loc & 5.31 & 1.51 & -0.85 & 0.44 \\
RLSV & 5.23 & 0.88 & 0.28 & 1.63 \\
RLRV & 6.06 & 1.21 & -0.35 & 0.25 \\
HQ & 5.90 & 1.10 & -0.33 & 0.17 \\
BS & 6.79 & 0.82 & -0.46 & 0.98 \\
FA & 5.25 & 0.86 & -0.09 & 0.48 \\
\hline
\end{tabular}

${ }^{1}$ Loc $=$ locomotion; RLSV $=$ rear leg side view; RLRV $=$ rear leg rear view; $\mathrm{HQ}=$ apparent hock quality; $\mathrm{BS}=$ apparent bone structure; FA $=$ foot angle.

ture, the following formula was used to transform heritabilities to the underlying continuous scale (Dempster and Lerner, 1950):

$$
h_{u}^{2}=\frac{h_{o b s}^{2} \times \bar{p}(1-\bar{p})}{\bar{z}^{2}},
$$

where $h_{u}^{2}=$ heritability on underlying continuous scale, $h_{o b s}^{2}=$ heritability on observed binary scale, $\bar{p}=$ incidence of disorder, and $\bar{z}=$ height of the ordinate of the normal distribution at the threshold point.

\section{RESULTS}

The mean, standard deviation, skewness, and kurtosis are shown in Table 5 for locomotion and the foot and leg conformation traits. All traits except RLSV had a negative skewness, meaning that the majority of the observations were distributed on the right side of the mean (i.e., toward the more desirable phenotype for all traits). The range of the kurtosis was between 0.17 and 1.63 , which is a relatively low kurtosis, reflecting the lack of possible extreme deviations, as the scale only ranges from 1 to 9 .

\section{Heritability and Variances}

Estimated heritabilities using univariate models were 0.01 for all 3 claw and leg health traits (on observable binary scale), 0.09 for locomotion, and ranged from 0.13 to 0.27 for the foot and leg conformation traits (Table 6). Similar estimates were obtained using bivariate models (results not shown). Heritabilities on the underlying continuous scale were $0.06,0.01$, and 0.04 for claw health, leg health, and absence of all claw and leg disorders, respectively.

Estimated heritabilities on the observed scale for the individual disorders were very low: $0.0005,0.0008$, $0.0098,0.0084$, and 0.0046 for interdigital dermatitis, laminitis, interdigital phlegmon, interdigital hyperplasia, and undefined leg disorders, respectively (convergence could not be reached for the remaining disorders). The heritability on the underlying continuous scale was $0.026,0.060$, and 0.038 for interdigital dermatitis, laminitis, and undefined leg disorders, respectively (the transformation for interdigital phlegmon and interdigital hyperplasmia gave unrealistically high heritabilities on the underlying scale, presumably because of the very low incidences).

\section{Genetic and Phenotypic Correlations}

The genetic correlation between claw health and leg health was 0.35 (Table 7) with a standard error of 0.12 . The highest genetic correlations were found between claw health and locomotion $(0.46 \pm 0.10)$ and between leg health and apparent hock quality $(0.42 \pm 0.09)$. There was also a moderate genetic correlation between claw health and RLRV (0.21 \pm 0.10$)$, whereas RLSV and foot angle were not genetically correlated with any of the investigated claw and leg health traits (Table 7). Phenotypic correlations were small and ranged from -0.05 to 0.09 (Table 8 ).

Table 6. Heritabilities $\left(h^{2}\right)$, their standard errors $\left(S E_{h}^{2}\right)$, genetic $\left(\sigma_{A}^{2}\right)$ and phenotypic $\left(\sigma_{P}^{2}\right)$ variances for different subcategories of claw and leg health, foot and leg conformation traits, and locomotion

\begin{tabular}{lcccc}
\hline Trait $^{1}$ & $h^{2}$ & $S E_{h}^{2}$ & $\sigma_{A}^{2}$ & $\sigma_{P}^{2}$ \\
\hline CH & 0.01 & 0.0005 & 0.0004 & 0.0331 \\
LH & 0.01 & 0.0004 & 0.0004 & 0.0133 \\
ALL & 0.01 & 0.0005 & 0.0008 & 0.0575 \\
Loc & 0.09 & 0.0028 & 0.2800 & 2.9200 \\
RLSV & 0.19 & 0.0034 & 0.1092 & 0.5757 \\
RLRV & 0.14 & 0.0038 & 0.1340 & 0.9328 \\
HQ & 0.22 & 0.0041 & 0.2516 & 1.1358 \\
BS & 0.27 & 0.0045 & 0.1564 & 0.5730 \\
FA & 0.13 & 0.0031 & 0.0832 & 0.6525 \\
\hline
\end{tabular}

${ }^{1} \mathrm{CH}=$ claw health; $\mathrm{LH}=$ leg health; ALL = absence of all claw and leg disorders; Loc $=$ locomotion; RLSV $=$ rear leg side view; RLRV = rear leg rear view; $\mathrm{HQ}=$ apparent hock quality; $\mathrm{BS}=$ apparent bone structure; $\mathrm{FA}=$ foot angle. 
Table 7. Genetic correlations $\left(\mathrm{r}_{\mathrm{g}}\right)$ and their standard errors (in parentheses) between subcategories of claw and leg health and locomotion and foot and leg conformation traits

\begin{tabular}{lccccccc}
\hline & \multicolumn{7}{c}{ Trait } \\
\cline { 2 - 7 } Trait $^{1}$ & LH & Loc & RLRV & RLSV & FA & HQ & BS \\
\hline CH & $0.35^{*}(0.12)$ & $0.46^{*}(0.10)$ & $0.21^{*}(0.10)$ & $-0.07(0.09)$ & $0.02(0.10)$ & $0.12(0.09)$ & $0.14(0.09)$ \\
LH & & $0.09(0.13)$ & $-0.07(0.11)$ & $-0.14(0.10)$ & $-0.17(0.11)$ & $0.42^{*}(0.09)$ & $0.26^{*}(0.10)$ \\
ALL & & $0.31^{*}(0.10)$ & $-0.12(0.09)$ & $-0.12(0.09)$ & $-0.04(0.10)$ & $0.30^{*}(0.04)$ & $0.23^{*}(0.08)$ \\
\hline
\end{tabular}

${ }^{1} \mathrm{CH}=$ claw health; $\mathrm{LH}=$ leg health; ALL = absence of all claw and leg disorders; Loc = locomotion; RLSV = rear leg side view; RLRV = rear leg rear view; $\mathrm{HQ}=$ apparent hock quality; $\mathrm{BS}=$ apparent bone structure; $\mathrm{FA}=$ foot angle.

*Significantly different from zero $(P<0.05)$.

Genetic correlations were also estimated for 5 individual disorders with locomotion. These correlations were often higher than genetic correlations between the subcategories of disorders and locomotion. The highest correlation was between interdigital dermatitis and locomotion $(-0.60)$ followed by that between interdigital hyperplasia and locomotion $(-0.53)$, laminitis and locomotion $(-0.51)$, interdigital phlegmon and locomotion $(-0.44)$, and finally between undefined leg disorders and locomotion $(-0.11)$. The standard error of these correlation estimates ranged from 0.10 to 0.25 .

The results from the selection index calculations showed that the accuracy (correlation between true and predicted breeding value for claw health) increased from 0.16 to 0.24 or 0.45 to 0.54 for a bull with 10 or 100 daughter-records, respectively, when considering correlated information from locomotion compared with only claw health. When RLRV was considered, in addition to locomotion, the accuracy was 0.25 or 0.54 for the bull with 10 or 100 daughter records, respectively.

\section{DISCUSSION}

The objective of this study was to estimate genetic correlations of claw and leg health with their potential indicator traits; namely, locomotion and foot and leg conformation traits, to establish whether the indicator traits could be used to improve genetic selection for the traits of main interest. Heritability estimates confirmed our expectation that claw and leg health traits were less heritable ( 0.01 on observed and $\leq 0.06$ on underlying scale) compared with locomotion and foot and leg conformation (ranged from 0.09 to 0.27 ). The estimated heritabilities for claw health were similar to or lower than previously reported findings by Huang and Shanks (1995; 0.054 to 0.135), van der Waaij et al. (2005; 0.01 to 0.1 on underlying liability scale), Harder et al. (2006; about 0.04 on underlying liability scale) and König et al. (2008; 0.07 to 0.11). In the present study, claw and leg health recordings were performed by veterinarians and on many more cows than in previous studies. Consequently, there was probably a tendency for only the most severe cases of claw and leg disorders to be registered. This created low frequencies of claw and, especially, leg health records.

Threshold models are usually recommended for analyses of binary traits with a presumed underlying continuous variable (e.g., Gianola, 1982), but were not used for the health traits in this study to make computation feasible. Logistic regression (e.g., Koenig et al., 2005) or recursive threshold models (e.g., König et al., 2008) could also have been considered for analyses of the health traits. Although use of linear models for binary traits may cause a small bias in breeding values (e.g., Carlén et al., 2006; Stock et al., 2007), especially for extreme breeding values, REML estimates of genetic parameters are expected to be unbiased (Mäntysaari et al., 1991). Those authors found in a simulation study that linear models performed equally well as threshold models for estimation of both heritabilities and genetic correlations, even at low incidence rates (i.e., 5\%). However, the more unbalanced data structure for the

Table 8. Phenotypic correlations of subcategories of claw and leg health with locomotion, and foot and leg conformation traits

\begin{tabular}{lcccrrrr}
\hline & \multicolumn{9}{c}{ Trait } \\
\cline { 2 - 7 } Trait $^{1}$ & LH & Loc & RLRV & RLSV & FA & HQ \\
\hline CH & -0.05 & 0.07 & 0.03 & 0.04 & 0.02 & 0.02 & 0.02 \\
LH & & 0.03 & 0.01 & 0.02 & 0.01 & 0.05 & 0.02 \\
ALL & & 0.09 & 0.05 & -0.05 & -0.01 & 0.04 & 0.03 \\
\hline
\end{tabular}

${ }^{1} \mathrm{CH}=$ claw health; $\mathrm{LH}=$ leg health; ALL = absence of all claw and leg disorders; Loc = locomotion; RLSV = rear leg side view; RLRV = rear leg rear view; $\mathrm{HQ}=$ apparent hock quality; $\mathrm{BS}=$ apparent bone structure; $\mathrm{FA}=$ foot angle. 
present data may have lead to less unbiased estimation. Although genetic correlations are comparable on the observed binary and underlying continuous scale (Vinson et al., 1976; Mäntysaari et al., 1991), heritabilities are not. Heritabilities on the observed binary scale are expected to be lower than those on the underlying continuous scale, especially at low incidence rates (Dempster and Lerner, 1950). Heritabilities were estimated on the underlying scale using threshold models in the studies by van der Waaij et al. (2005) and by Harder et al. (2006); and these estimates are therefore expected to be higher than those found in our study on the observed binary scale. However, comparable results were found when heritability estimates were transformed to the underlying continuous scale using the DempsterLerner formula.

In the studies by van der Waaij et al. (2005) and Boettcher et al. (1998), records for claw health were scored by claw trimmers, as presence of a claw disorder or assessed by classifiers as severity of lameness on a locomotion scoring scale, respectively. Using data recorded by claw trimmers would extend the claw health data available for Danish Holsteins, which is currently only based on veterinary treatments, and make future estimation of genetic parameters more reliable. In Sweden the heritability for claw disorders based on claw trimming data was estimated to be 0.06 using linear models (Naeslund et al., 2008). Recording of claw health data by claw trimmers is to be initiated on a trial basis in Denmark based on the Swedish methods of recording.

The heritabilities for locomotion and foot and leg conformation traits agreed closely with previous findings by Boelling et al. (2001), van Dorp et al. (2004), and van der Waaij et al. (2005). Apparent hock quality and bone structure are only assessed in the Nordic countries and were only comparable with results from Boelling et al. (2001). Heritability estimates depend on the trait definition and the quality of trait recording (e.g., the precision of the classification). Here, all recordings for locomotion and foot and leg conformation traits were performed by 6 trained classifiers. To ensure consistency in their scoring, the classifiers harmonized their scoring by training together once a year. Furthermore, the recordings were corrected for classifier-month-year during statistical analyses.

The locomotion and conformation data set contain records of a selected set of cows (see Materials). Even though this is impossible to prevent, especially for locomotion, it may cause biased estimates of genetic parameters. Furthermore, it is not known whether estimated genetic correlations are representative for herds without locomotion recording, although conformation in tie stalls and free stalls can be considered the same trait (Lassen and Mark, 2008). However, many of the herds without locomotion records had tie stalls, and the frequency of such housing systems have been rapidly declining in Denmark during the past 2 decades. As this tendency is expected to continue, the estimated parameters for locomotion and conformation may, therefore, better represent future production circumstances in Denmark. The data used for this study included more cows from more herds and was less selected than that used for previous studies investigating claw and leg health.

The low genetic correlation (0.35) between claw health and leg health suggests that they are different traits and indicates that it may be beneficial to revise the current practice of combining the disorders into one trait for genetic evaluation. However, low frequencies of (especially) leg disorders would make such a genetic evaluation difficult. Although claw and leg health are considered different traits, they may still be presented as part of the same sub-index to the breeders. In such an index, focus should be not only on healthy claws and legs, but also on functional feet and legs that allow the cow to move freely and unhindered; for this reason, locomotion should also be a trait of direct interest.

Estimates of genetic correlations between locomotion and claw health and between RLRV and claw health were positive, which means that good locomotion (see Table 1) and parallel rear legs rear view were genetically associated with healthy claws. The correlations might be explained by alterations in weight distribution from the lateral to the medial claw, as a consequence of pain due to presence of a claw disorder (Boettcher and Dekkers, 1997; van der Waaij et al., 2005). The moderate size of these genetic correlations, together with higher heritabilities of indicator traits, showed that locomotion and RLRV are useful indicator traits for improved claw health. Although RLRV was less strongly correlated with claw health than locomotion, it had higher heritability and is recorded more frequently than locomotion. This means that for some animals, RLRV could be a more useful indicator trait than locomotion and vice versa, which would justify including it in addition to locomotion in genetic evaluations of claw health. Both traits are more frequently recorded and are usually recorded earlier or at the same time as recording of claw and leg disorders, which is an advantage. The genetic correlation between locomotion and RLRV is favorable and around 0.73 (Boelling et al., 2007).

Hock quality and bone structure were useful indicator traits for leg health, whereas locomotion and RLRV were not useful. That is, the genetic correlations were 0.42 and 0.26 for hock quality and bone structure, respectively, indicating that less cartilage and liquid in 
the hocks as well as finer apparent bone structure were genetically associated with healthy legs.

The study found no significant correlation between RLSV and any of the subcategories of claw health. The same applied to foot angle. This may be because RLSV and foot angle have intermediate optima. Further research could investigate whether deviations from the optimum would be associated with claw and leg health.

The genetic correlations between the individual disorders and locomotion ranged from -0.44 (interdigital phlegmon) to -0.60 (interdigital dermatitis), except for undefined leg disorders $(-0.11)$. This indicates that locomotion could be more effective in breeding against certain disorders such as interdigital dermatitis compared with interdigital phlegmon. It also indicates that the concerned disorders are different traits. The low phenotypic correlations could be partly due to the low frequencies of claw and leg disorders.

Genetic evaluations are useful for claw and health traits despite their low heritabilities, especially if evaluated simultaneously with informative indicator traits. Although genetic evaluations can be improved by accounting for the binary nature of the health traits (e.g., by using threshold models), it is probably more important to have multiple-trait evaluations including the most informative indicator traits. Although computationally demanding, multiple-trait analyses are feasible today for a limited number of threshold and Gaussian traits.

\section{CONCLUSIONS}

Claw and leg health were different but correlated traits (0.35). Locomotion and RLRV were useful indicator traits for claw health (0.46 and 0.21 , respectively), whereas apparent hock quality and bone structure were useful indicators for leg health (0.42 and 0.26, respectively). Inclusion of these indicator traits in genetic evaluation for the health traits of interest enables more accurate selection and can increase genetic progress for claw and leg health

\section{ACKNOWLEDGMENTS}

Ulrik Sander Nielsen (National Centre, the Danish Cattle Federation, Skejby, Denmark) is acknowledged for his guidance with the statistical analysis and data extraction; the anonymous reviewers are acknowledged for helpful comments.

\section{REFERENCES}

Alban, L. 1994. Lameness in Danish dairy cows; frequency and possible risk factors. Prev. Vet. Med. 22:213-225.

Boelling, D., A. Fogh, and U. Sander Nielsen. 2007. Locomotion as a new trait: First results from Denmark. Interbull Bull. 37:175178.

Boelling, D., P. Madsen, and J. Jensen. 2001. Genetic parameters of foot and leg traits in future AI bulls. Acta Agric. Scand. Anim. Sci. 51:122-128.

Boettcher, P. J., and J. C. M. Dekkers. 1997. Indirect selection for resistance to locomotive disorders in dairy cattle. Interbull Bull. 15:123-129.

Boettcher, P. J., J. C. M. Dekkers, L. D. Warnick, and S. J. Wells. 1998. Genetic analysis of clinical lameness in dairy cattle. J. Dairy Sci. $81: 1148-1156$.

Booth, C. J., L. D. Warnick, Y. T. Gröhn, D. O. Maizon, C. L. Guard, and D. Janssen. 2004. Effect of lameness on culling in dairy cows. J. Dairy Sci. 87:4115-4122.

Carlén, E., U. Emanuelson, and E. Strandberg. 2006. Genetic evaluation of mastitis in dairy cattle using linear models, threshold models and survival analysis: A simulation study. J. Dairy Sci. 89:4049-4057.

Dempster, E. R., and I. M. Lerner. 1950. Heritability of threshold characters. Genetics 35:212-236.

Enting, H., D. Kooij, A. A. Dijkhuizen, R. B. M. Huirne, and E. N. Noordhuizen-Stassen. 1997. Economic losses due to clinical lameness in dairy cattle. Livest. Prod. Sci. 49:259-267.

Ettema, J. F., and S. Østergaard. 2006. Economic decision making on prevention and control of clinical lameness in Danish dairy herds. Livest. Prod. Sci. 102:92-106.

Garbarino, E. J., J. A. Hernandes, J. K. Shearer, C. A. Risco, and W. W. Thatcher. 2004. Effect of lameness on ovarian activity in postpartum Holstein cows. J. Dairy Sci. 87:4123-4131.

Gianola, D. 1982. Theory and analysis of threshold characters. J. Anim. Sci. 54:1079-1096.

Green, L. E., V. J. Hedges, Y. H. Schukken, R. W. Blowey, and A. J. Packington. 2002. The impact of clinical lameness on the milk yield of dairy cows. J. Dairy Sci. 85:2250-2256.

Harder, B., J. Bennewitz, D. Hinrichs, and E. Kalm. 2006. Genetic parameters for health traits and their relationship to different persistency traits in German Holstein dairy cattle. J. Dairy Sci. 89:3202-3212.

Huang, Y. C., and R. D. Shanks. 1995. Within-herd estimates of heritability for six hoof characteristics and impact of dispersion of discrete severity scores on estimates. Livest. Prod. Sci. 44:107114.

Jensen, J., E. A. Mäntysaari, P. Madsen, and R. Thompson. 1997. Residual maximum likelihood estimation of (co) variance components in multivariate mixed linear models using average information. J. Ind. Soc. Agric. Stat. 49:215-236.

Koenig, S., A. R. Sharifi, H. Wentrot, D. Landmann, M. Eise, and H. Simianer. 2005. Genetic parameters of claw and foot disorders estimated with logistic models. J. Dairy Sci. 88:3316-3325.

König, S., X. L. Wu, D. Gianola, B. Heringstad, and H. Simianer. 2008. Exploration of relationships between claw disorders and milk yield in Holstein cows via recursive linear and threshold models. J. Dairy Sci. 91:395-406.

Lassen, J., and T. Mark. 2008. Short Communication: Genotype by housing interaction for conformation and workability traits in Danish Holsteins. J. Dairy Sci. 91:4424-4428.

Madsen, P., and J. Jensen. 1993. Package for Analysing Multivariate Mixed Models. Danish Institute of Agricultural Sciences, Research Centre Foulum, Tjele, Denmark.

Mäntysaari, E. A., R. L. Quaas, and Y. T. Gröhn. 1991. Simulation study on covariance component estimation for two binary traits in an underlying continuous scale. J. Dairy Sci. 74:580-591.

Naeslund, S., J. H. Jakobsen, J.-A. Eriksson, and E. Strandberg. 2008. Genetic parameters for dairy cattle claw health traits recorded by claw trimmers. Proc. 59th Annu. Mtg. EAAP, Vilnius, Lithuania. 
Published online at www. eaap.org/ (Vilnius presentations/session 35) Accessed Feb. 10, 2009.

Stock, K. F., I. Hoeschele, and O. Distl. 2007. Estimation of genetic parameters and prediction of breeding values for multivariate threshold and continuous data in a simulated horse population using Gibbs sampling and residual maximum likelihood. J. Anim. Breed. Genet. 124:308-319.

Strudsholm, F. M. B., A. Fogh, D. Boelling, U. S. Nielsen, and J. Pedersen. 2007. Årsstatistik-avl 2006-2007. U. S. Nielsen, ed. National Centre, Danish Cattle Federation, Department of Breeding Systems, Aarhus, the Netherlands. van der Waaij, E. H., M. Holzhauer, E. Ellen, C. Kamphuis, and G. de Jong. 2005. Genetic parameters for claw disorders in Dutch dairy cattle and correlations with conformation traits. J. Dairy Sci. 88:3672-3678.

van Dorp, T. E., P. Boettcher, and L. R. Schaeffer. 2004. Genetics of locomotion. Livest. Prod. Sci. 90:247-253.

Vinson, W. E., J. M. White, and R. H. Kliewer. 1976. Overall classification as a selection criterion for improving categorically scored components of type in Holsteins. J. Dairy Sci. 59:21042114 . 